\title{
Nitrogen enrichment weakens ecosystem stability through decreased species asynchrony and population stability in a temperate grassland
}

\author{
YUNHAI ZHANG ${ }^{1}$, MICHEL LOREAU ${ }^{2}$, XIAOTAO LÜ ${ }^{3}$, NIANPENG HE $^{4}$, \\ GUANGMING ZHANG ${ }^{1}$ and XINGGUO HAN ${ }^{1,3}$ \\ ${ }^{1}$ State Key Laboratory of Vegetation and Environmental Change, Institute of Botany, Chinese Academy of Sciences, Beijing \\ 100093, China, ${ }^{2}$ Centre for Biodiversity Theory and Modelling, Station d'Ecologie Expérimentale du CNRS, Moulis 09200, France, \\ ${ }^{3}$ State Key Laboratory of Forest and Soil Ecology, Institute of Applied Ecology, Chinese Academy of Sciences, Shenyang 110164, \\ China, ${ }^{4}$ Synthesis Research Center of Chinese Ecosystem Research Network, Institute of Geographic Sciences and Natural \\ Resources Research, Chinese Academy of Sciences, Beijing 100101, China
}

\begin{abstract}
Biodiversity generally promotes ecosystem stability. To assess whether the diversity-stability relationship observed under ambient nitrogen $(\mathrm{N})$ conditions still holds under $\mathrm{N}$ enriched conditions, we designed a 6-year field experiment to test whether the magnitude and frequency of $\mathrm{N}$ enrichment affects ecosystem stability and its relationship with species diversity in a temperate grassland. Results of this experiment showed that the frequency of $\mathrm{N}$ addition had no effect on either the temporal stability of ecosystem and population or the relationship between diversity and stability. Nitrogen addition decreased ecosystem stability significantly through decreases in species asynchrony and population stability. Species richness was positively associated with ecosystem stability, but no significant relationship between diversity and the residuals of ecosystem stability was detected after controlling for the effects of the magnitude of $\mathrm{N}$ addition, suggesting collinearity between the effects of $\mathrm{N}$ addition and species richness on ecosystem stability, with the former prevailing over the latter. Both population stability and the residuals of population stability after controlling for the effects of the magnitude of $\mathrm{N}$ addition were positively associated with ecosystem stability, indicating that the stabilizing effects of component populations were still present after $\mathrm{N}$ enrichment. Our study supports the theory predicting that the effects of environmental factors on ecosystem functioning are stronger than those of biodiversity. Understanding such mechanisms is important and urgent to protect biodiversity in mediating ecosystem functioning and services in the face of global changes.
\end{abstract}

Keywords: asynchrony, biodiversity, community stability, complementarity, insurance hypothesis, nitrogen addition frequency, nitrogen deposition, portfolio effect, species stability

Received 4 August 2015 and accepted 12 October 2015

\section{Introduction}

Scientists have long been interested in whether species diversity is associated with ecosystem stability (May, 1974; McNaughton, 1977; Loreau, 2010; Tilman \& Snell-Rood, 2014; Hautier et al., 2015). A huge body of recent research on this topic has focused on the relationship between species diversity and ecosystem temporal stability (Jiang \& $\mathrm{Pu}, 2009$; Loreau, 2010; Tilman et al., 2014), and suggested a number of underlying mechanisms for this relationship, such as the insurance effect (species asynchrony or compensation) (Yachi \& Loreau, 1999; Bai et al., 2004; Loreau \& de Mazancourt, 2013), overyielding (Hector et al., 2010), the portfolio effect (statistical averaging)

Correspondence: Xiaotao Lü and Xingguo Han, tel. +86 24 83970301, fax +86 24 83970300, e-mail: lvxiaotao@iae.ac.cn (XL); xghan@ibcas.ac.cn $(\mathrm{XH})$
(Tilman et al., 1998), and the selection effect (Loreau \& Hector, 2001). Rapidly increasing human population (Gerland et al., 2014) and consumption (Westhoek et al., 2014) have generated overexploitation of the remaining natural and managed ecosystems, resulting in high rates of species extinction and ecosystem simplification (Vitousek et al., 1997; Rands et al., 2010). These rapid changes call for an urgent understanding of how ecosystem structure, functioning, and services will be altered following realistic biodiversity loss (Cardinale et al., 2012; Balvanera et al., 2014; Isbell et al., 2015).

Nitrogen $(\mathrm{N})$ enrichment by both atmospheric deposition (Stevens et al., 2004) and fertilization (Bobbink et al., 2010) resulting from human activities is a serious threat to biodiversity, with consequences for ecosystem functioning and services (Vitousek et al., 1997; Isbell et al., 2011; Stevens et al., 2015). Nitrogen 
enrichment generally reduces plant species diversity but increases primary production (Hooper et al., 2012). Theoretically, nutrition enrichment may destabilize the ecosystem (Rosenzweig, 1971). Whether the relationship between biodiversity and ecosystem stability observed under ambient $\mathrm{N}$ conditions in both natural and artificial ecosystems is still present under $\mathrm{N}$ enriched conditions is an important but unresolved question. Many previous reports on diversity-stability relationships in controlled $\mathrm{N}$ addition experiments (e.g. Tilman \& Downing, 1994; Grman et al., 2010; Song \& Yu, 2015) did not carefully separate the specific effect of diversity on stability from the confounding effects of $\mathrm{N}$ availability on diversity and stability (Huston, 1997; Loreau, 1998; Wardle et al., 2000; Lepš, 2004; Duffy, 2009). Using diversity as a covariate or testing its effect on the residuals of ecosystem stability after controlling the effects of $\mathrm{N}$ treatment are ways to explore the effect of diversity on stability with realistic losses of species under $\mathrm{N}$ enrichment (Huston, 1997; Yang et al., 2012).

Moreover, the impacts of enriched $\mathrm{N}$ on ecosystem properties might be dependent not only on the magnitude but also on the frequency of $\mathrm{N}$ inputs (Zhang et al., 2014a,b). Atmospheric $\mathrm{N}$ deposition occurs as many frequent events, each of which adding a relatively small dose of reactive $\mathrm{N}$ to the ecosystem (Aneja et al., 2001; Smith et al., 2009). In contrast, in many previous studies, reactive $\mathrm{N}$ is usually added during the growing season with only a few additions per year (e.g. Tilman \& Downing, 1994; Grman et al., 2010; Yang et al., 2012; Hautier et al., 2014; Song \& Yu, 2015). Thus, results from previous controlled $\mathrm{N}$ experimental studies might lead to a potentially biased assessment for the effects of atmospheric $\mathrm{N}$ deposition on species diversity and ecosystem stability, due to the excessively large and infrequent pulses of $\mathrm{N}$ added (Smith et al., 2009). For example, species richness decreased less steeply at higher frequency of $\mathrm{N}$ addition in a steppe (Zhang et al., 2014b), suggesting that previous $\mathrm{N}$ addition studies may overestimate the rate of biodiversity loss following atmospheric $\mathrm{N}$ deposition. The response of ecosystem stability may also depend on the frequency of $\mathrm{N}$ deposition, as indicated by the contrasting effects of fertilizers with different releasing rates on the temporal stability of the same ecosystem (Yang et al., 2011; Wang et al., 2013). Understanding the effects of $\mathrm{N}$ addition frequency on ecosystem stability and on the diversity-stability relationship would help accurately assess its impacts on ecosystem functioning and services under enriched $\mathrm{N}$ scenarios (e.g. $\mathrm{N}$ fertilization, atmospheric $\mathrm{N}$ deposition). However, the effect of the frequency of $\mathrm{N}$ additions on ecosystem stability and on the diversity-stability relationship has not been tested so far.

Based on a long-term experiment that included nine rates (from 0 to $50 \mathrm{~g} \mathrm{~N} \mathrm{~m}^{-2} \mathrm{yr}^{-1}$ ) crossed with two frequencies (two inputs per year or monthly) of $\mathrm{N}$ addition in the form of ammonium nitrate $\left(\mathrm{NH}_{4} \mathrm{NO}_{3}\right)$ in a temperate steppe, we aim to evaluate the effects of the rate and frequency of $\mathrm{N}$ addition on ecosystem stability and on the relationship between biodiversity and ecosystem stability. Based on our previous studies showing that a higher frequency of $\mathrm{N}$ addition had less negative effects on species richness (Zhang et al., 2014b) and species colonization (Zhang et al., 2015b) in the same experimental setup, we hypothesized that (i) the amount of $\mathrm{N}$ addition would reduce stability, (ii) a lower frequency of $\mathrm{N}$ addition would result in a smaller temporal stability at both the population and ecosystem levels, and (iii) frequent $\mathrm{N}$ addition would weaken the effects of the amount of $\mathrm{N}$ addition on the relationship between species richness and ecosystem stability. To our knowledge, this is the first study that jointly considers the effects of the frequency and rate of $\mathrm{N}$ addition on ecosystem stability and on the diversity-stability relationship with realistic species extinctions under $\mathrm{N}$ enrichment.

\section{Materials and methods}

\section{Study site}

The field experiment was carried out in a temperate steppe near the Inner Mongolia Grassland Ecosystem Research Station (IMGERS; $116^{\circ} 14^{\prime} \mathrm{E}, 43^{\circ} 13^{\prime} \mathrm{N}$ ), which is located in the Xilin River Basin, Inner Mongolia Autonomous Region, China. A 50 ha natural grassland has been fenced since 1999 to exclude large animal grazing. The topography of the experimental area is relatively flat, with an elevation ranging from 1255 to $1260 \mathrm{~m}$. Long-term (1980-2013) mean annual temperature was $0.9^{\circ} \mathrm{C}$, with mean monthly temperatures ranging from $-21.4{ }^{\circ} \mathrm{C}$ in January to $19.7^{\circ} \mathrm{C}$ in July. Long-term mean annual precipitation was $351.4 \mathrm{~mm}$, with approximately $72.8 \%$ falling during the growing season (May to August). During the growing seasons from 2009 to 2013, precipitation varied more than twofold, from 167.2 to $343.5 \mathrm{~mm}$, and mean monthly temperature ranged from 16.2 to $22.7{ }^{\circ} \mathrm{C}$. The soil is classified as Calcic-Orthic Aridisol by the U.S. soil classification system. The plant community contained about 60 species. The mean plant community peak aboveground biomass was $176.34 \mathrm{~g} \mathrm{~m}^{-2} \mathrm{yr}^{-1}$, ranging from 68.49 to $342.3 \mathrm{~g} \mathrm{~m}^{-2} \mathrm{yr}^{-1}$. Stipa grandis and Leymus chinensis together accounted for $>60 \%$ of the total peak aboveground biomass in the community. The annual ambient atmosphere $\mathrm{N}$ deposition was $<1.0 \mathrm{~g} \mathrm{~N} \mathrm{~m}^{-2}$ in this region (Zhu et al., 2015). No fertilizer was received prior to this experiment. 


\section{Experimental design}

The experiment was established in September 2008, following a randomized complete block design (Zhang et al., $2014 \mathrm{~b})$. There were nine rates $(0,1,2,3,5,10,15,20$, and $50 \mathrm{~g} \mathrm{~N} \mathrm{~m}^{-2} \mathrm{yr}^{-1}$ ) crossed with two frequencies (2 times $\mathrm{yr}^{-1}, 2 \mathrm{~N}$ additions $\mathrm{yr}^{-1}$ vs. monthly, $12 \mathrm{~N}$ additions $\mathrm{yr}^{-1}$ ) of $\mathrm{N}$ addition. There was also a control treatment (without additions of $\mathrm{N}$, water, or sand) to detect the effects of water and sand additions (see next paragraph) by comparing responses between the control and $0 \mathrm{~N}$ addition plots. Each plot is $8 \mathrm{~m} \times 8 \mathrm{~m}$. Hence, there were 19 experimental treatments in total, all present in each of the 10 blocks (10 replicates).

$\mathrm{NH}_{4} \mathrm{NO}_{3}(>99 \%)$ addition started on September 1, 2008 and continued on the first day of each month thereafter for the high-frequency treatment $\left(12 \mathrm{~N}\right.$ additions $\left.\mathrm{yr}^{-1}\right)$, and started on November 1, 2008 and continued on the first day of June and November thereafter for the low-frequency treatment ( $2 \mathrm{~N}$ additions $\mathrm{yr}^{-1}$ ). Thus, total annual $\mathrm{N}$ loadings between the two treatments were equal after the monthly $\mathrm{N}$ addition in August. From May to October, fertilizer was weighed and mixed with purified water $(9.0 \mathrm{~L}$ total for all treatments receiving water: either $9.0 \mathrm{~L}$ once in June or $1.5 \mathrm{~L}$ monthly from May to October), and sprinkled evenly using a sprayer to each plot to simulate wet $\mathrm{N}$ deposition. It was estimated that $<1 \mathrm{~mm}$ of water was added to each plot annually, except for the control plots, which had no water added. Control plots received no water whereas water was added to $0 \mathrm{~N}$ plots. In winter (from November to April), $\mathrm{NH}_{4} \mathrm{NO}_{3}$ was mixed with sand (mixture of $\mathrm{NH}_{4} \mathrm{NO}_{3}$ and sand ensured an even distribution of additional $\mathrm{N}$ in every plot; $0.5 \mathrm{~kg}$ total for each treatment receiving sand: either $0.5 \mathrm{~kg}$ once in November or $0.08 \mathrm{~kg}$ monthly from November to April) and spread uniformly by hand. Sand was sieved to $<1 \mathrm{~mm}$, dipped in hydrochloric acid, washed in purified water, and then oven-dried at $120^{\circ} \mathrm{C}$ for $24 \mathrm{~h}$. To avoid otherwise potentially confounding effects, plots received the same amount of water and sand, regardless of whether they received the high- or low-frequencies of $\mathrm{N}$ addition treatment.

\section{Field sampling}

Aboveground net primary productivity (ANPP) of the community was estimated annually from peak aboveground plant biomass, which is an acceptable approximation for ANPP in this region as aboveground plant tissues die during the winter season (Bai et al., 2004). Aboveground biomass was sampled each year from 2008-2013 between 10 and 15 August using a $0.5 \mathrm{~m} \times 2 \mathrm{~m}$ quadrat (Zhang et al., 2015a), which was randomly placed in each plot without spatial overlap of quadrats among years and at least $50 \mathrm{~cm}$ inside the border of each plot to avoid edge effects. All living vascular plants were sorted to species, oven-dried at $65^{\circ} \mathrm{C}$ for $48 \mathrm{~h}$ to a constant weight, and then weighed. Plant species richness (number of species) was recorded in the same strip of aboveground biomass measured per year (Zhang et al., 2014b).

\section{Statistical analyses}

Community ANPP and species richness were not significantly different prior to treatment (i.e. year 2008) between the plots assigned to the various treatments (All $P>0.1$ ).

Ecosystem/species temporal stability in each plot was defined as $\mu / \sigma$ (Lehman \& Tilman, 2000), where $\mu$ is the temporal mean of ecosystem/species ANPP and $\sigma$ is its standard deviation across the years 2009-2013. To ensure normality and homogeneity, ecosystem stability, species stability, ecosystem $\mu$ and ecosystem $\sigma$ were $\ln$ transformed before analyses. Population stability was defined as the average of species stability across all species in the community.

Community-wide species asynchrony (Loreau \& de Mazancourt, 2008) was quantified as $1-\varphi_{b}=1-\sigma_{b_{T}}^{2} /\left(\sum_{i=1}^{S} \sigma_{b_{i}}\right)^{2}$, where $\sigma_{b_{T}}^{2}$ is the variance of ecosystem ANPP and $\sigma_{b_{i}}$ is the standard deviation of ANPP of species $i$ in a community with $S$ species over the years 2009-2013. This measure of species asynchrony ranges between 0 (perfect synchrony) and 1 (perfect asynchrony). A significant increase in community stability with species asynchrony suggests that species asynchrony contributes to stability (Loreau \& de Mazancourt, 2013).

We also examined the effect of the mean-variance scaling relationship (Taylor's power law) on ecosystem stability. This relationship has the form $\sigma^{2}=\mathrm{cm}^{2}$, where $\sigma^{2}$ is the variance in species ANPP, $c$ is a constant, $m$ is the average species ANPP, and $z$ is the scaling coefficient (Tilman et al., 1998). When $2>z>1$, diversity is expected to enhance ecosystem stability (Tilman et al., 1998). We also used each species' residual from Taylor's power law to estimate its relative stability at each $\mathrm{N}$ addition rate. A larger negative residual indicated that a species was relatively more stable (Grman et al., 2010). The relationship between dominance and stability was calculated from Pearson's correlation coefficient between species relative abundances and these residuals. A negative value of Pearson's correlation coefficient suggested a positive effect of dominance on stability (Grman et al., 2010).

Two-way analysis of variance (ANOVA) was used to test the effects of the frequency and rate of $\mathrm{N}$ addition on ecosystem stability, population stability, ecosystem $\mu$, ecosystem $\sigma$, and species asynchrony across the years 2009-2013 (Table S1).

As $\mathrm{N}$ enrichment impacted on both plant species richness and stability simultaneously, it is likely to hide the specific effects of diversity on stability (Huston, 1997; Loreau, 1998; Wardle et al., 2000; Duffy, 2009). Therefore, ANCovas were employed to test treatment and species richness effects on ecosystem stability, population stability, ecosystem $\mu$, ecosystem $\sigma$, and species asynchrony. Because there were no interactive effects of treatments $\times$ species richness on these factors (Table S2), ANCOVAs were employed, in which the rate and the frequency of $\mathrm{N}$ addition were the fixed variables and species richness was the covariate (Table 1). As the frequency of $\mathrm{N}$ addition and the interaction between the rate and frequency of $\mathrm{N}$ addition showed no effects on the above-mentioned variables (Tables 1, S1, S2; all $P>0.1$ ), values of the $\mathrm{N}$ frequency addition were combined in further analyses (20 replicates for each $\mathrm{N}$ addition rate). Nitrogen-induced changes in species 
Table 1 Results of analysis of covariance (ANCOVA) (without the treatment $\times$ species richness interaction term) for the effects of average community species richness (SR), the frequency $(\mathrm{F})$ and rate $(\mathrm{N})$ of nitrogen addition, and their interactions on the ecosystem temporal stability, ecosystem mean $(\mu)$ of aboveground net primary productivity, ecosystem standard deviation $(\sigma)$, population stability, and species asynchrony. Degrees of freedom (df), $F$-test values and $P$-values are given

\begin{tabular}{|c|c|c|c|c|c|c|c|c|c|c|c|}
\hline & \multirow[b]{2}{*}{$\mathrm{df}$} & \multicolumn{2}{|c|}{$\begin{array}{l}\text { Ecosystem } \\
\text { stability }\end{array}$} & \multicolumn{2}{|c|}{ Ecosystem $\mu$} & \multicolumn{2}{|c|}{ Ecosystem $\sigma$} & \multicolumn{2}{|c|}{$\begin{array}{l}\text { Population } \\
\text { stability }\end{array}$} & \multicolumn{2}{|c|}{ Asynchrony } \\
\hline & & $F$ & $P$ & $F$ & $P$ & $F$ & $P$ & $F$ & $P$ & $F$ & $P$ \\
\hline SR & 1,161 & 0.0 & 0.859 & 7.4 & 0.007 & 1.0 & 0.325 & 0.0 & 0.889 & 0.0 & 0.893 \\
\hline $\mathrm{F}$ & 1,161 & 0.0 & 0.852 & 2.0 & 0.162 & 0.2 & 0.665 & 0.0 & 0.876 & 1.3 & 0.250 \\
\hline $\mathrm{N}$ & 8,161 & 16.5 & $<0.001$ & 38.4 & $<0.001$ & 34.7 & $<0.001$ & 5.0 & $<0.001$ & 3.3 & 0.002 \\
\hline $\mathrm{F} \times \mathrm{N}$ & 8,161 & 0.8 & 0.590 & 1.4 & 0.185 & 0.7 & 0.733 & 0.6 & 0.768 & 0.5 & 0.827 \\
\hline
\end{tabular}

richness, stability, species asynchrony, ecosystem $\mu$, and ecosystem $\sigma$ were calculated as the difference between $\mathrm{N}$ addition and unmanipulated plots. Residuals from regressions of variables with $\mathrm{N}$ addition (or species richness) were used to explore the remaining effects of diversity (or $\mathrm{N}$ addition). Path analysis was further conducted to evaluate the relationships between $\mathrm{N}$ addition rate, species richness, species asynchrony, population stability, and ecosystem stability. All statistics were performed through sPSs software package (SPSs 18.0 for windows, SPSS Inc., Chicago, IL, USA).

\section{Results}

\section{Temporal stability and species asynchrony}

The frequency of $\mathrm{N}$ addition had no effect on ecosystem stability, population stability, ecosystem $\mu$, ecosystem $\sigma$, and species asynchrony (Table S1, all $P>0.05)$. Regardless of the frequency of $\mathrm{N}$ addition, ecosystem stability (Fig. $1 \mathrm{a} ; F_{1,178}=152.3, P<0.0001$; $R^{2}=0.46$ ), species richness (Fig. $1 \mathrm{~b} ; \quad F_{1,178}=88.2$, $P<0.0001 ; R^{2}=0.33$ ), population stability (Fig. 1c; $\left.F_{1,178}=53.3, P<0.0001 ; R^{2}=0.23\right)$, and species asynchrony (Fig. 2a; $F_{1,178}=7.5, P<0.01 ; R^{2}=0.04$ ) significantly decreased with increasing $\mathrm{N}$ addition rates, whereas ecosystem $\mu$ (Fig. $2 b ; \quad F_{1,178}=471.0$, $P<0.0001 ; \quad R^{2}=0.73$ ) and ecosystem $\sigma$ (Fig. 2b; $\left.F_{1,178}=361.4, \quad P<0.0001 ; \quad R^{2}=0.67\right) \quad$ significantly increased. As expected, ecosystem $\mu$ and $\sigma$ were positively correlated (Fig. $2 c ; F_{1,178}=662.5, \quad P<0.0001$; $R^{2}=0.79$ ). The rate of increase in ecosystem $\mu$ with increasing $\mathrm{N}$ addition rate was slower than that of ecosystem $\sigma$ (i.e. smaller slope; $F_{1,356}=83.6$, $P<0.0001$ ), indicating that increasing rates of $\mathrm{N}$ addition weakened ecosystem stability via a decrease in the mean-to-variance ratio.

Log-transformed values of the variance of species ANPP were positively correlated to log-transformed values of its mean (Fig. 3a; All $P<0.0001$ ). The scaling coefficient $z$ of the mean-variance scaling relationship was 1.669 and 1.594 for $\mathrm{N}$-enriched and unmanipulated plots, respectively (Fig. 3a). Ecosystems with $\mathrm{N}$ addition had a greater scaling coefficient $z$ compared with unmanipulated plots (Fig. 3a; $F_{1,2192}=14.7 P<0.0001$ ). Coefficient $z$ increased with the $\mathrm{N}$ addition rate (Fig. 3b; $F_{1,7}=69.4, \quad P<0.0001 ; \quad R^{2}=0.91$ ). Species dominance (relative ANPP in the community) and species relative temporal stability (residuals from Taylor's power law) were negatively correlated (Fig. 3c) and the slopes of the regressions between species dominance and relative stability were marginally significantly increased by the increases in $\mathrm{N}$ addition rates (Fig. 3d; $F_{1,7}=4.3, P<0.08 ; R^{2}=0.38$ ), indicating that increases in the rate of $\mathrm{N}$ addition decreased the effects of dominant species on species stability.

Population stability was positively correlated with ecosystem stability (Fig. $4 \mathrm{a} ; F_{1,178}=63.2, \quad P<0.0001$; $R^{2}=0.26$ ). The residuals (from Fig. 1c) of population stability after controlling for the effects of the magnitude of $\mathrm{N}$ addition was also positively associated with ecosystem stability (Fig. $4 \mathrm{~b} ; \quad F_{1,178}=8.4, \quad P<0.01$; $\left.R^{2}=0.05\right)$. These suggest that $\mathrm{N}$ enrichment did not alter the stabilizing effects of component populations on ecosystem stability.

Both species asynchrony (Fig. 4c; $F_{1,178}=60.0$, $P<0.0001 ; R^{2}=0.25$ ) and the residuals (from Fig. 2a) of species asynchrony after controlling for $\mathrm{N}$ addition rates were positively correlated with ecosystem stability (Fig. 4 d; $F_{1,178}=31.2, P<0.0001 ; R^{2}=0.15$ ). $\mathrm{N}$-induced changes in species asynchrony were also positively associated with changes in ecosystem stability (Fig. S1a; $F_{1,178}=44.2, P<0.0001 ; R^{2}=0.22$ ). This indicates that species asynchrony enhanced ecosystem stability under both unmanipulated and $\mathrm{N}$ enriched conditions. Residuals (from Fig. 2a) of species asynchrony were not correlated with ecosystem $\mu$ (Fig. 4e; $\left.F_{1,178}=1.3, P>0.1 ; R^{2}=0.01\right)$ and were negatively correlated with ecosystem $\sigma$ (Fig. 4e; $F_{1,178}=15.4$, $\left.P<0.0001 ; R^{2}=0.08\right)$, suggesting that the stabilizing effects of species asynchrony on ecosystem occurred through decreases in ecosystem variance. 

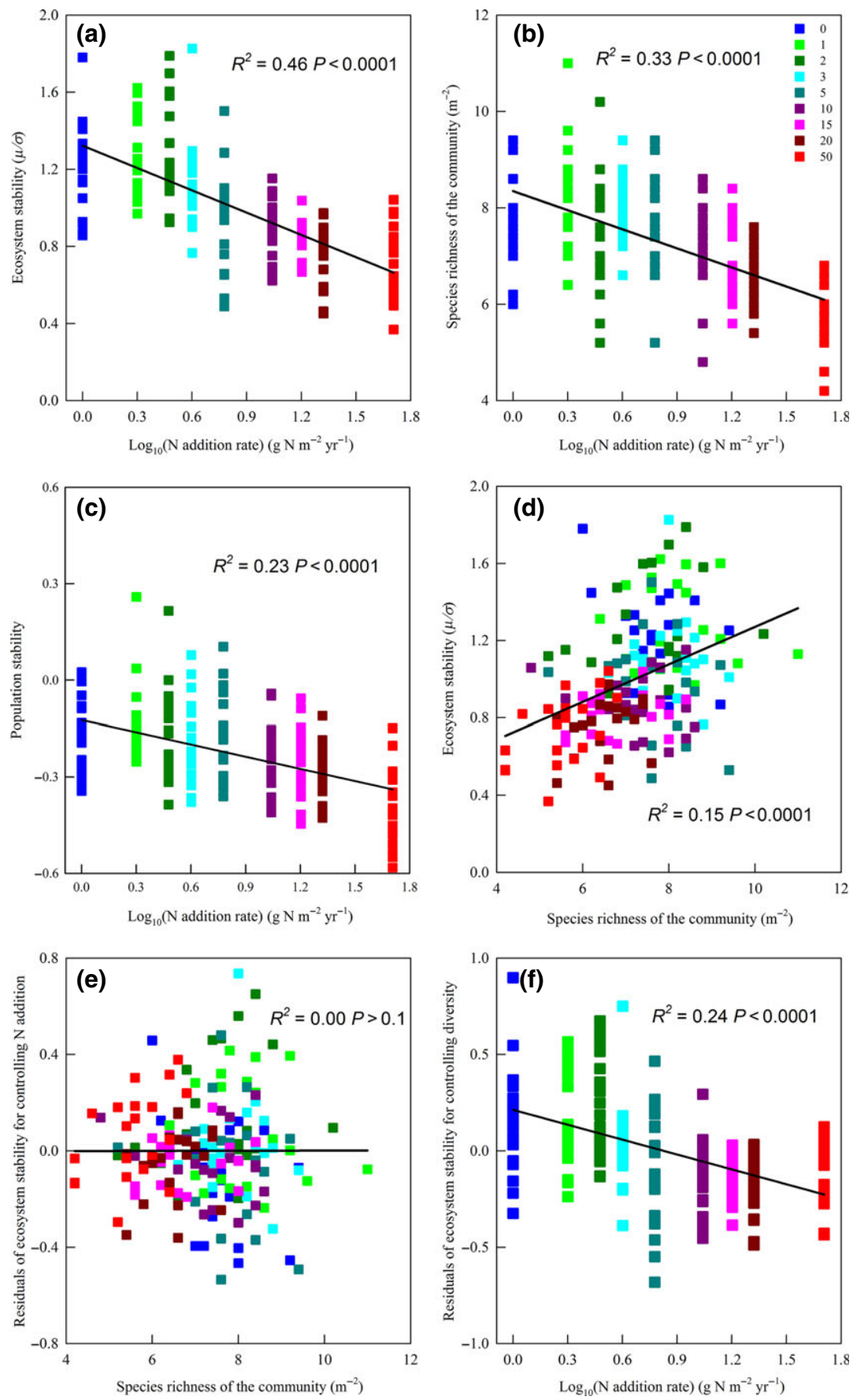

Fig. 1 Ecosystem temporal stability and species richness. (a) Ecosystem temporal stability of aboveground net primary productivity (ANPP), (b) species richness (number $\mathrm{m}^{-2}$ ), and (c) population stability decreased with increases of $\mathrm{N}$ addition rate. (d) Ecosystem stability and (e) residuals (from Fig. 1a) of ecosystem stability as a function of the average species richness of the community. (f), Residuals (from Fig. 1d) of ecosystem stability decreased with increases of $\mathrm{N}$ addition rate. Colors corresponded to increasing $\mathrm{N}$ addition rate $\left(\mathrm{g} \mathrm{N} \mathrm{m} \mathrm{yr}^{-1}\right)$.

\section{Diversity-stability relationship}

The frequency of $\mathrm{N}$ addition did not alter the diversity-stability relationship (Table $1 ; \quad F_{1,161}=0.0$, $P>0.1$ ). Species richness was positively correlated with ecosystem stability (Fig. $1 \mathrm{~d} ; \quad F_{1,178}=32.4$, $\left.P<0.0001 ; R^{2}=0.15\right)$ and the loss of diversity after $\mathrm{N}$ addition led to a reduction of ecosystem stability (Fig. S1b; $F_{1,158}=36.1, P<0.0001 ; R^{2}=0.19$ ), suggesting that species richness promotes ecosystem stability. 

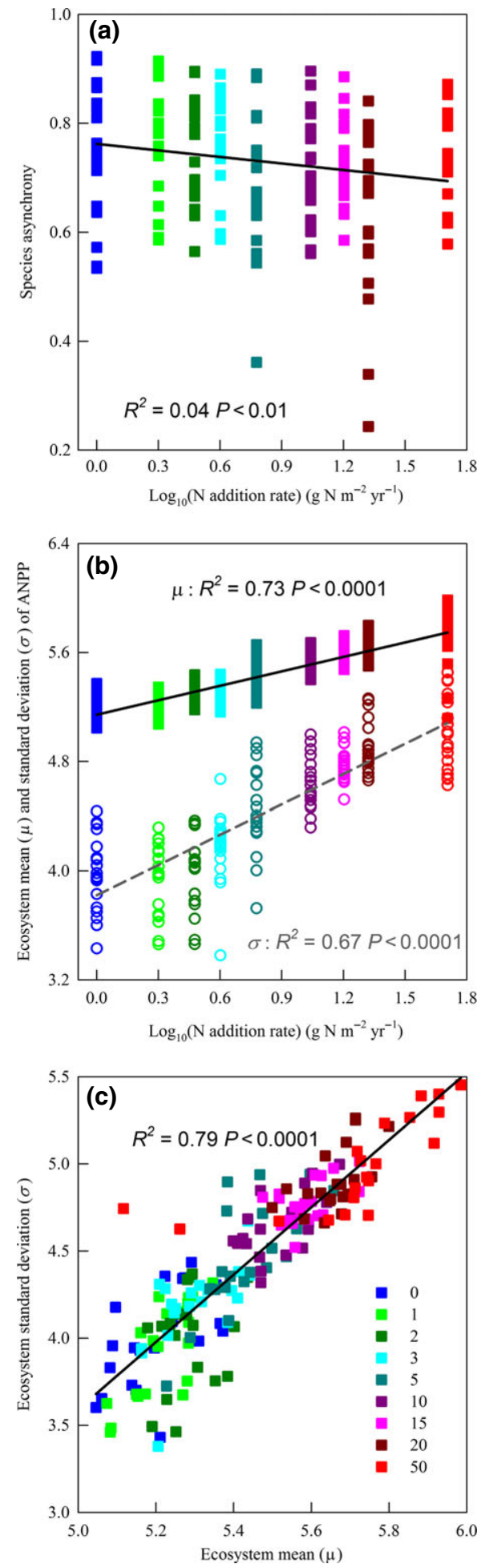

Fig. 2 Effects of $\mathrm{N}$ enrichment on species asynchrony, ecosystem mean and its standard deviation, and mean-variance scaling relationship. (a) Changes of species asynchrony with increases of $\mathrm{N}$ addition rate, respectively. (b) Ecosystem mean ( $\mu$; squares) and its standard deviation ( $\sigma$; cycles) of ANPP increased with increases of $\mathrm{N}$ addition rate, respectively. (c) Relationship between ecosystem $\mu$ and ecosystem $\sigma$.
But species richness was not related to the residuals (from Fig. 1a) of ecosystem stability after controlling for the effects of $\mathrm{N}$ addition (Fig. 1e; $F_{1,178}=0.0$, $P>0.1 ; R^{2}=0.00$ ). In contrast, the residuals (from Fig. 1d) of ecosystem stability after controlling for diversity were still reduced by increases in $\mathrm{N}$ addition rates (Fig. 1f; $F_{1,178}=57.1, P<0.0001 ; R^{2}=0.24$ ), indicating the effect of $\mathrm{N}$ addition on ecosystem stability was stronger than that of diversity.

Species richness was negatively correlated with both ecosystem $\mu$ (Fig. 4f; $F_{1,178}=89.0, P<0.01 ; R^{2}=0.33$ ) and ecosystem $\sigma$ (Fig. 4f; $F_{1,178}=63.2, \quad P<0.0001$; $\left.R^{2}=0.26\right)$. The negative slope between species richness and ecosystem $\mu$, however, was greater than that between species richness and ecosystem $\sigma$ (Fig. 4f; $\left.F_{1,356}=12.3, \quad P<0.001\right)$, suggesting that diversity enhanced stability through a decrease in ecosystem $\mu$ and an increase in the mean-to-variance ratio under $\mathrm{N}$ addition.

The loss of diversity after $\mathrm{N}$ addition led to an increase in ecosystem $\mu$ (Fig. S1c; $F_{1,158}=86.3$, $P<0.0001 ; R^{2}=0.35$ ) and ecosystem $\sigma$ (Fig. S1c; $\left.F_{1,158}=61.2, \quad P<0.0001 ; \quad R^{2}=0.30\right)$. The slope of changes in ecosystem $\mu$ was greater than that of changes in ecosystem $\sigma$ (Fig. S1c; $F_{1,316}=14.1$ $P<0.0001$ ), again indicating that the reduced stability due to $\mathrm{N}$-induced decreases in species richness was caused by a decrease in the mean-to-variance ratio.

Path analysis showed that $\mathrm{N}$ addition was the main factor determining ecosystem stability (Fig. 5). There were also significant indirect effects of $\mathrm{N}$ addition on ecosystem stability through increases in species asynchrony and population stability (Fig. 5), but no indirect effect of $\mathrm{N}$ addition on stability through diversity was detected.

\section{Discussion}

In our long-term multi-level, 2-frequency $\mathrm{N}$ addition experiment that mimicked a realistic biodiversity loss scenario, we found that the effects of $\mathrm{N}$ addition were stronger than those of diversity on the temporal stability of ANPP. To our knowledge, this work is the first to test the simultaneous effects of the frequency and rate of $\mathrm{N}$ addition on the temporal stability of ecosystems and populations and on the diversity-stability relationship. Our results showed that $\mathrm{N}$ enrichment decreased ecosystem temporal stability, mainly through its negative impacts on the asynchronous growth between species and on the stabilizing effects of component populations. In contrast, the frequency of $\mathrm{N}$ addition did not alter the temporal stability of ecosystem and population and the diversity-stability relationship. 

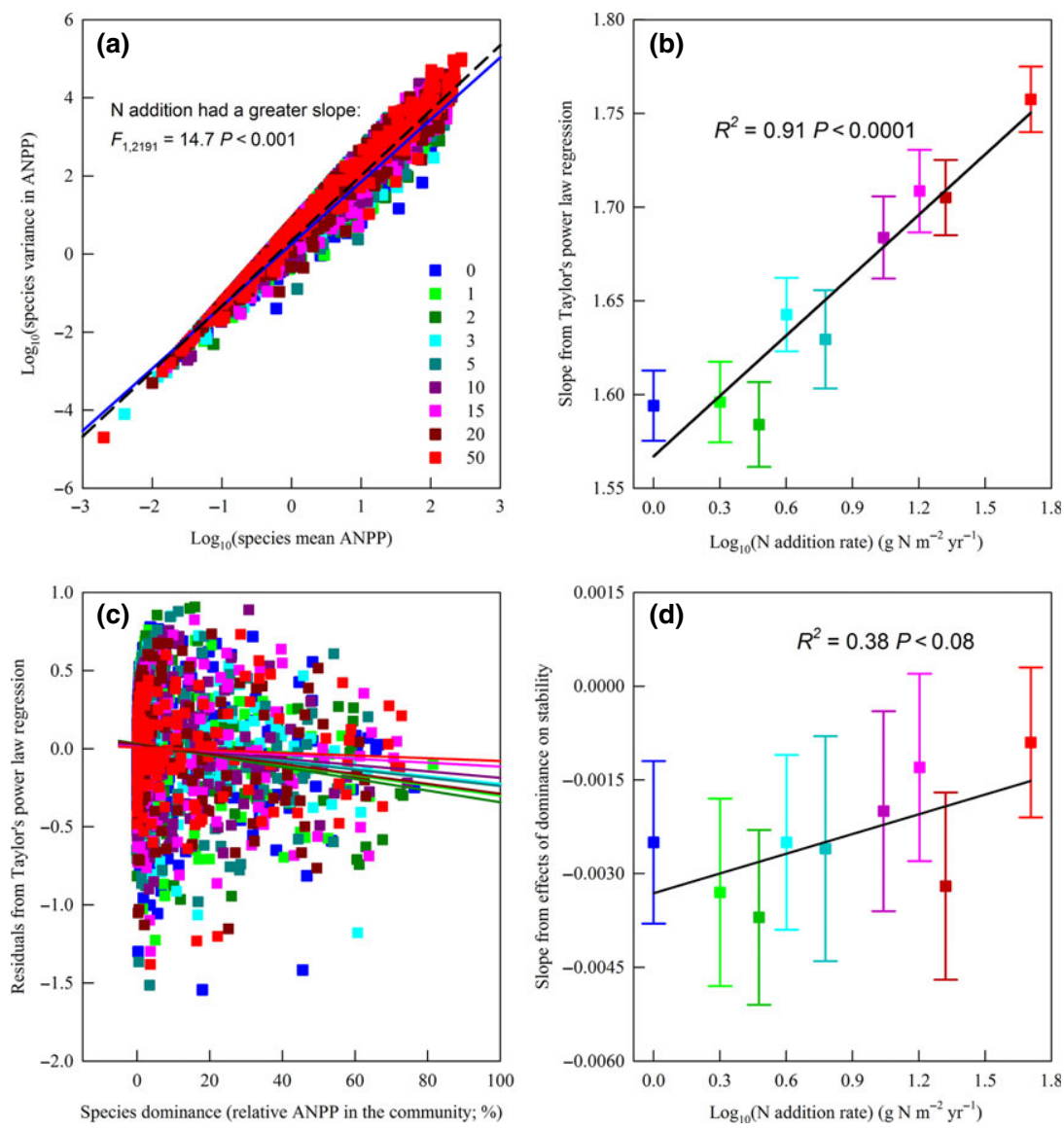

Fig. 3 Mean-variance scaling relationship and species dominance effects. (a) Coefficient $(z)$ of mean-variance scaling relationships in unmanipulated (solid line) and $\mathrm{N}$ addition (dashed line) plots. (b) Slope (z) from Taylor's power law regression increased with increases of $\mathrm{N}$ addition rate. (c) The relationship between species dominance (relative ANPP in the community) and species relative temporal stability (residuals from Taylor's power law regression). (d) Effects of the rate of $\mathrm{N}$ addition on the slope (from effects of species dominance on stability in Fig. 3c).

\section{Effects of the frequency of $N$ addition on ecosystem stability}

Neither ecosystem temporal stability nor the diversitystability relationship was altered by the frequency of $\mathrm{N}$ addition. Ecosystem temporal stability was quantified by the ratio between the mean and standard deviation of ANPP (Lehman \& Tilman, 2000), both of which did not vary between the two frequencies of $\mathrm{N}$ addition (Table S1). Our results showed that the effects of the frequency of $\mathrm{N}$ addition were much smaller than those of the rate of $\mathrm{N}$ addition. The stronger species loss at lower frequency of $\mathrm{N}$ addition did not affect ANPP (Zhang et al., 2015a) because of the negligible biomass production of species lost (generally $<5 \%$ of the total aboveground biomass). Previous studies found that the ecosystem stability was determined by dominant species rather than by rare ones, at least in the short term (Smith \& Knapp, 2003; Polley et al., 2007; Sasaki \& Lauenroth, 2011). Moreover, species asynchrony, which promotes ecosystem stability, did not differ between the two frequencies of $\mathrm{N}$ addition. Together, these results suggest that it is the total dosage, rather than the frequency of $\mathrm{N}$ enrichment, that affects ecosystem stability and the diversity-stability relationship. Because of the short duration of this study (5 years), the longterm effects of the frequency of $\mathrm{N}$ addition still need to be tested.

\section{Effects of the rate of $N$ addition on ecosystem stability}

By contrast, the rate of $\mathrm{N}$ addition had a significant negative effect on ecosystem stability. As temporal stability is defined as the ratio of the temporal mean of ANPP to its standard deviation, a decrease in ecosystem stability may be caused by a decrease in the mean, an increase in the standard deviation, or both. In agreement with Hautier et al. (2014), we found that the decrease in ecosystem stability due to $\mathrm{N}$ enrichment resulted from an increase in the mean and a larger increase in the 

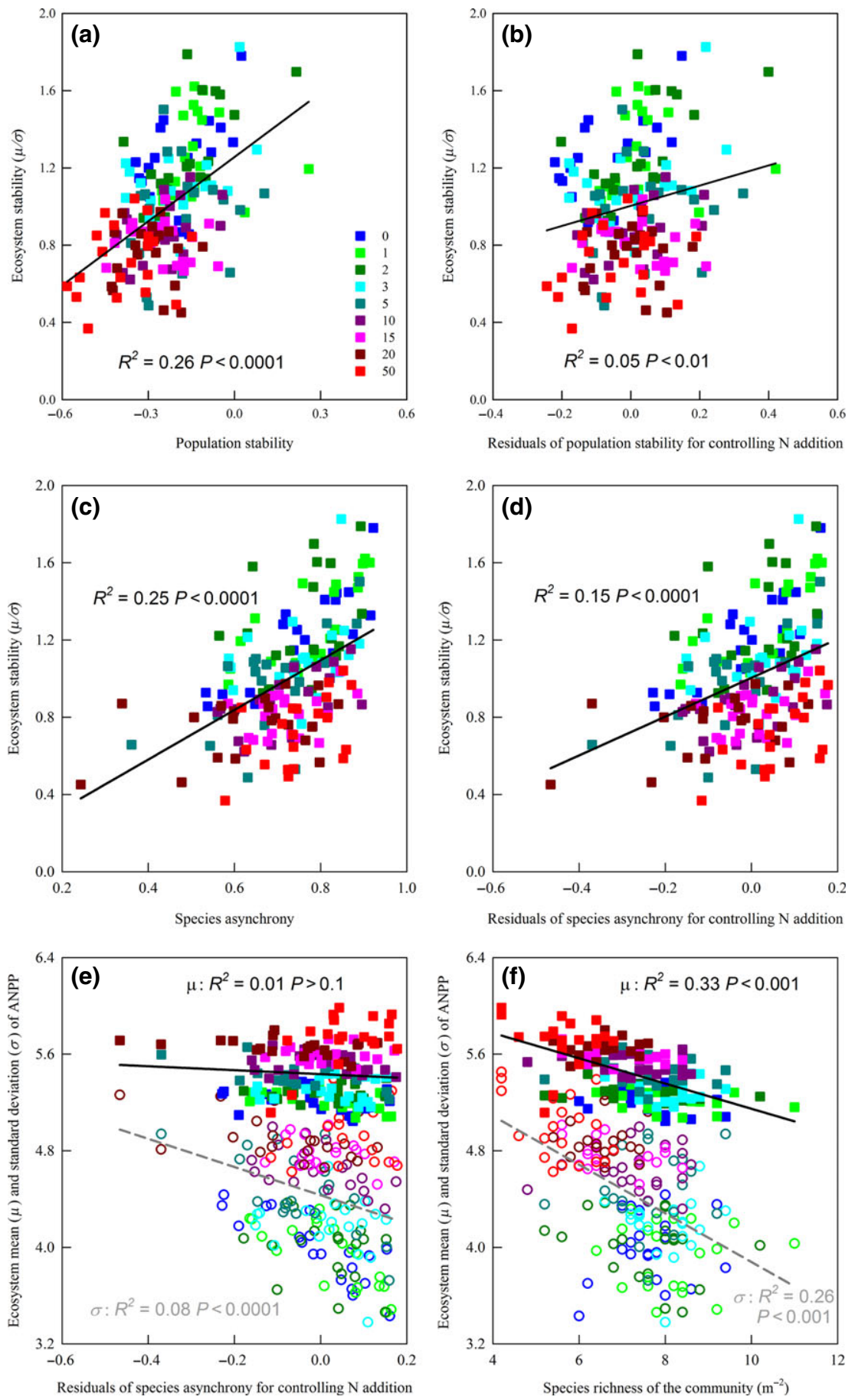

Fig. 4 Possible mechanisms of stabilizing ecosystem. (a) Relationship between population stability and ecosystem stability. (b) Residuals (from Fig. 1c) of population stability were positively associated with ecosystem stability. (c) Species asynchrony was positively associated with ecosystem stability. (d) Residuals (from Fig. 2a) of species asynchrony was positively associated with ecosystem stability. (e) Residuals (from Fig. 2a) of species asynchrony associated with ecosystem mean ( $\mu$; squares) and ecosystem standard deviation $(\sigma$; cycles). (f) Relationship between species richness and ecosystem $\mu$ (squares) and ecosystem $\sigma$ (cycles), respectively.

standard deviation. We also found that species dominance affected ecosystem stability as there was a negative relationship between species relative ANPP and species relative stability. This result is consistent with the findings of Grman et al. (2010), who reported that dominant species were more stable than 


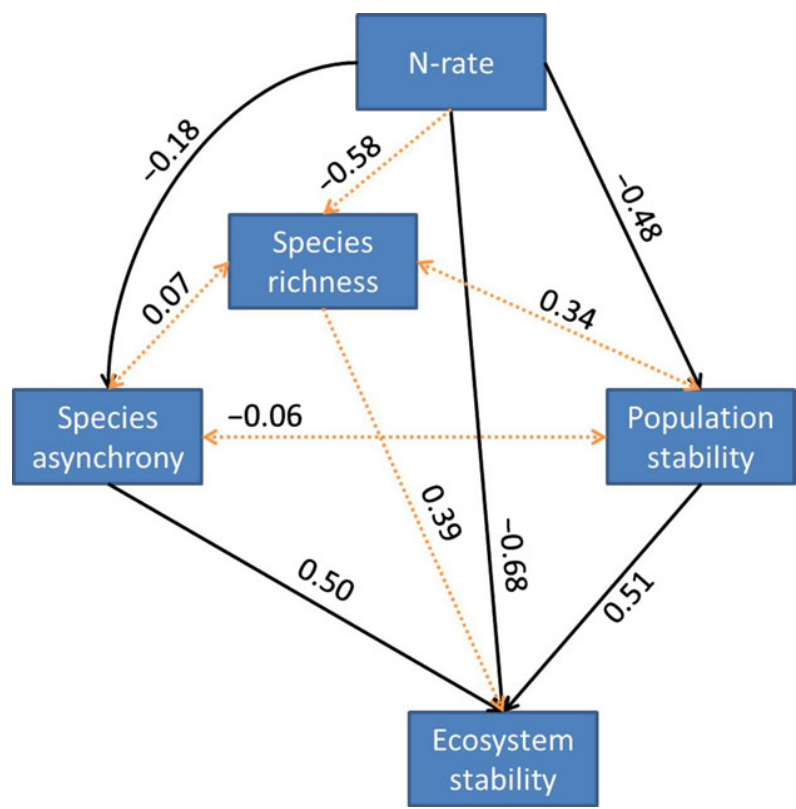

Fig. 5 Path chart illustrating the effect of $\mathrm{N}$ addition, species asynchrony, and population stability related to ecosystem temporal stability. Correlation coefficients are labeled. Solid and dotted lines are significant $(P<0.05)$ and non-significant $(P>0.05)$ paths, respectively.

subordinate species under both ambient and enriched $\mathrm{N}$ conditions in southwestern Michigan, USA. In our study, the slopes of these regressions were marginally significantly increased by increased $\mathrm{N}$ addition rates. This indicates that increases in the rate of $\mathrm{N}$ addition decreased the effects of dominant species on species stability and thus reduced average population stability. Our results are consistent with most previous $\mathrm{N}$ addition studies (Tilman, 1996; Yang et al., 2012), but in sharp contrast with a few studies that reported either a negative effect (Yang et al., 2011) or no effect (Lepš, 2004; Grman et al., 2010) on ecosystem stability. For example, Yang et al. (2011) reported a positive effect of $\mathrm{N}$ addition on ecosystem stability in an alpine grassland, mainly via increasing the abundance of a stable dominant species through a selection effect.

Greater ecosystem stability is generally associated with stronger species asynchrony in global grasslands under both natural and $\mathrm{N}$ enrichment conditions (Hector et al., 2010; Hautier et al., 2014). Our findings provide robust evidence for a positive relationship between species asynchrony and both ecosystem temporal stability and the residuals of ecosystem stability after controlling the effects of $\mathrm{N}$ addition, indicating that such relationship is not altered by enhanced $\mathrm{N}$ inputs. Species asynchrony promotes ecosystem stability via compensating growth between species or plant functional groups (Bai et al., 2004; Song \& Yu, 2015). In the same experimental setup, our previous results showed that the decreased ANPP of some species can be compensated by an increased ANPP of other species (Zhang et al., 2015a). For example, the decreased ANPP of four species, Cleistogenes squarrosa, Koeleria cristata, Carex korshinskyi, and Allium tenuissimum by $\mathrm{N}$ enrichment was be compensated by the increases in ANPP of other three species, L. chinensis, Agropyon cristatum, and Chenopodium glaucum. Thus, our results support the stabilizing effect of temporal complementarity between species on ecosystem stability (Loreau \& de Mazancourt, 2013).

We also found a mean-variance scaling relationship consistent with a positive effect of biodiversity on ecosystem stability $(1<z<2)$, in agreement with previous studies (Lepš, 2004; Grman et al., 2010; Song \& $\mathrm{Yu}, 2015)$. The scaling coefficient of this relationship was significantly greater in $\mathrm{N}$ enrichment plots $(z=1.669)$ than that in ambient $\mathrm{N}$ plots $(z=1.594)$, as previously found by Lepš (2004). This suggests that dominant species, i.e. species that have a high mean biomass, are more variable in $\mathrm{N}$ enriched conditions, thereby resulting in a greater $z$ value. In the same experimental set-up, Zhang et al. (2015a) reported that the ANPP of dominant species was more strongly altered, either positively or negatively, than that of rare species by increased $\mathrm{N}$ addition rates. Thus, dominant species might be more sensitive to environmental fluctuations under $\mathrm{N}$ enrichment. However, the detailed mechanisms that generate this increased variability of dominant species are still unclear. Further work is needed to test these mechanisms thoroughly. Based on a neutral model, Loreau (2010) predicted that the scaling coefficient $z$ should be related to communitywide species synchrony, $\phi_{b}$, through the equation $z=2+\ln \varphi_{b} / \ln S$, where $S$ is species richness. Thus, this scaling coefficient should be negatively correlated with species asynchrony. Our experimental results support this prediction $\left(F_{2,177}=850.0\right.$, $P<0.0001 ; R^{2}=0.91$ ), which means that this relationship exists not only under the neutral assumption but also in real communities.

\section{Diversity-stability relationship and its underlying mechanisms under $N$ enrichment}

In agreement with previous studies (Tilman, 1996; Yang et al., 2012; Hautier et al., 2015), we found a positive relationship between biodiversity and ecosystem temporal stability after $\mathrm{N}$ addition. This positive diversity-stability relationship, however, was no longer detected after controlling for the effects of $\mathrm{N}$ addition in our study, thus challenging a recent study on diversity-stability relationships in Minnesota grasslands 
(Hautier et al., 2015). Hautier et al. (2015) suggested that biodiversity affects ecosystem temporal stability independently of various anthropogenic environmental drivers, including $\mathrm{N}$ addition, water addition, $\mathrm{CO}_{2}$ enriched, fire and herbivory exclusion, and water addition, at the Cedar Creek Ecosystem Science Reserve. Here, we recalculated the residuals of changes in the response ratio of ecosystem temporal stability as a function of the changes in the response ratio of species richness after controlling for the effects of $\mathrm{N}$ enrichment using the data in Hautier et al. (2015). We found that these two variables were not significantly correlated $\left(F_{1,6}=0.2, P>0.1\right.$, see Fig. S2). Thus, their results do not provide strong evidence that the effect of $\mathrm{N}$ addition on ecosystem stability is mediated by changes in diversity, and are in line with ours. But we found that the $R^{2}$ of the regression between $\mathrm{N}$ addition rates and ecosystem stability largely decreased from 0.46 to 0.24 when the effect of species richness on ecosystem stability was controlled for, which suggests that species richness might promote ecosystem stability despite its relatively weak effect. Our results supports Loreau's (1998) theoretical prediction that diversity effects on ecosystem functioning do exist but that they should generally be weaker than, and masked by, the effects of environmental factors. Thus, the positive effect of diversity on ecosystem stability is likely to be masked by the stronger effect of $\mathrm{N}$ addition, particularly when large doses of $\mathrm{N}$ fertilizers are added once or when low doses were added by the experiments lasted for a long time.

In conclusion, the negative effect of $\mathrm{N}$ addition on ecosystem stability was independent of the frequency of $\mathrm{N}$ addition in our 5 year field experiment. Our study demonstrates that $\mathrm{N}$ enrichment weakens ecosystem stability and the diversity-stability relationship in a temperate grassland. It also suggests that there might be strong collinearity between the effects of $\mathrm{N}$ addition and those of species richness on ecosystem stability, with the former prevailing over the latter. Our work illustrates that reactive $\mathrm{N}$ inputs tend to weaken the insurance effects and species temporal complementarity through reduced species asynchrony and reduced stabilizing effects of component populations.

\section{Acknowledgements}

We thank Xiaoliang Wang, Jianjun Chen, Jinlian Wang, Minglu Rong and others for their contributions to data collection, Dr. Zhenqing Li for data analysis, the IMGERS for provided meteorological data, and two anonymous reviewers for provided helpful insights on this manuscript. This work was supported by the National Natural Science Foundation of China (NSFC; 31570469) and China Postdoctoral Science Foundation funded project (2014M560134 and 2015T80153) to YZ, the TULIP
Laboratory of Excellence (ANR-10-LABX-41) to ML, Youth Innovation Promotion Association CAS (2014174) to $\mathrm{XL}$, and NSFC (31430016) to XH.

\section{References}

Aneja VP, Roelle PA, Murray GC et al. (2001) Atmospheric nitrogen compounds II: emissions, transport, transformation, deposition and assessment. Atmospheric Environment, 35, 1903-1911.

Bai YF, Han XG, Wu JG, Chen ZZ, Li LH (2004) Ecosystem stability and compensatory effects in the Inner Mongolia grassland. Nature, 431, 181-184.

Balvanera P, Siddique I, Dee L et al. (2014) Linking biodiversity and ecosystem services: current uncertainties and the necessary next steps. BioScience, 64, 49-57.

Bobbink R, Hicks K, Galloway J et al. (2010) Global assessment of nitrogen deposition effects on terrestrial plant diversity: a synthesis. Ecological Applications, 20, 30-59.

Cardinale BJ, Duffy JE, Gonzalez A et al. (2012) Biodiversity loss and its impact on humanity. Nature, 486, 59-67.

Duffy JE (2009) Why biodiversity is important to the functioning of real-world ecosystems. Frontiers in Ecology and the Environment, 7, 437-444.

Gerland P, Raftery AE, Ševčíková H et al. (2014) World population stabilization unlikely this century. Science, 346, 234-237.

Grman E, Lau JA, Schoolmaster DR, Gross KL (2010) Mechanisms contributing to stability in ecosystem function depend on the environmental context. Ecology Letters, 13, 1400-1410.

Hautier Y, Seabloom EW, Borer ET et al. (2014) Eutrophication weakens stabilizing effects of diversity in natural grasslands. Nature, 508, 521-525.

Hautier Y, Tilman D, Isbell F, Seabloom EW, Borer ET, Reich PB (2015) Anthropogenic environmental changes affect ecosystem stability via biodiversity. Science, 348, 336-340.

Hector A, Hautier Y, Saner P et al. (2010) General stabilizing effects of plant diversity on grassland productivity through population asynchrony and overyielding. Ecology, 91, 2213-2220.

Hooper DU, Adair EC, Cardinale BJ et al. (2012) A global synthesis reveals biodiversity loss as a major driver of ecosystem change. Nature, 486, 105-108.

Huston MA (1997) Hidden treatments in ecological experiments: re-evaluating the ecosystem function of biodiversity. Oecologia, 110, 449-460.

Isbell F, Calcagno V, Hector A et al. (2011) High plant diversity is needed to maintain ecosystem services. Nature, 477, 199-202.

Isbell F, Tilman D, Polasky S, Loreau M (2015) The biodiversity-dependent ecosystem service debt. Ecology Letters, 18, 119-134.

Jiang L, Pu ZC (2009) Different effects of species diversity on temporal stability in single - trophic and multitrophic communities. The American Naturalist, 174, 651-659.

Lehman CL, Tilman D (2000) Biodiversity, stability, and productivity in competitive communities. The American Naturalist, 156, 534-552.

Lepš J (2004) Variability in population and community biomass in a grassland community affected by environmental productivity and diversity. Oikos, 107, 64-71.

Loreau M (1998) Biodiversity and ecosystem functioning: a mechanistic model. Proceedings of the National Academy of Sciences of the United States of America, 95, $5632-5636$.

Loreau M (2010) From Population to Ecosystem: Theoretical Foundations for a New Ecological Synthesis. Princeton University Press, Princeton and Oxford.

Loreau M, de Mazancourt C (2008) Species synchrony and its drivers: neutral and nonneutral community dynamics in fluctuating environments. The American Naturalist, 172, E48-E66.

Loreau M, de Mazancourt C (2013) Biodiversity and ecosystem stability: a synthesis of underlying mechanisms. Ecology Letters, 16, 106-115.

Loreau M, Hector A (2001) Partitioning selection and complementarity in biodiversity experiments. Nature, $\mathbf{4 1 2}, 72-76$

May RM (1974) Stability and Complexity in Model Ecosystems. Princeton University Press, Princeton, Oxford

McNaughton SJ (1977) Diversity and stability of ecological communities: a comment on the role of empiricism in ecology. The American Naturalist, 111, 515-525.

Polley HW, Wilsey BJ, Derner JD (2007) Dominant species constrain effects of species diversity on temporal variability in biomass production of tallgrass prairie. Oikos, 116, 2044-2052.

Rands MRW, Adams WM, Bennun L et al. (2010) Biodiversity conservation: challenges beyond 2010. Science, 329, 1298-1303.

Rosenzweig ML (1971) Paradox of enrichment: destabilization of exploitation ecosystems in ecological time. Science, 171, 385-387. 
Sasaki T, Lauenroth W (2011) Dominant species, rather than diversity, regulates temporal stability of plant communities. Oecologia, 166, 761-768.

Smith MD, Knapp AK (2003) Dominant species maintain ecosystem function with non-random species loss. Ecology Letters, 6, 509-517.

Smith MD, Knapp AK, Collins SL (2009) A framework for assessing ecosystem dynamics in response to chronic resource alterations induced by global change. Ecology, 90, 3279-3289.

Song MH, Yu FH (2015) Reduced compensatory effects explain the nitrogen-mediated reduction in stability of an alpine meadow on the Tibetan Plateau. New Phytologist, 207, 70-77.

Stevens CJ, Dise NB, Mountford JO, Gowing DJ (2004) Impact of nitrogen deposition on the species richness of grasslands. Science, 303, 1876-1879.

Stevens CJ, Lind EM, Hautier Y et al. (2015) Anthropogenic nitrogen deposition predicts local grassland primary production worldwide. Ecology, 96, 1459-1465.

Tilman D (1996) Biodiversity: population versus ecosystem stability. Ecology, 77, 350-363.

Tilman D, Downing JA (1994) Biodiversity and stability in grasslands. Nature, 367, 363-365.

Tilman D, Snell-Rood EC (2014) Diversity breeds complementarity. Nature, 515, $44-45$.

Tilman D, Lehman CL, Bristow CE (1998) Diversity-stability relationships: statistical inevitability or ecological consequence? The American Naturalist, 151, 277-282.

Tilman D, Isbell F, Cowles JM (2014) Biodiversity and ecosystem functioning. Annual Review of Ecology, Evolution, and Systematics, 45, 471-493.

Vitousek PM, Aber JD, Howarth RW et al. (1997) Human alteration of the global nitrogen cycle: sources and consequences. Ecological Applications, 7, 737-750.

Wang HD, Zhang LL, Zhu ZH (2013) Effects of clipping and fertilizing on the relationships between species diversity and ecosystem functioning and mechanisms of community stability in alpine meadow. Chinese Journal of Plant Ecology, 37, 279-295.

Wardle DA, Huston MA, Grime JP et al. (2000) Biodiversity and ecosystem function: an issue in ecology. Bulletin of the Ecological Society of America, 81, 235-239.

Westhoek H, Lesschen JP, Rood T et al. (2014) Food choices, health and environment: effects of cutting Europe's meat and dairy intake. Global Environmental Change, 26, 196-205.

Yachi S, Loreau M (1999) Biodiversity and ecosystem productivity in a fluctuating environment: the insurance hypothesis. Proceedings of the National Academy of Sciences of the United States of America, 96, 1463-1468.

Yang ZL, Van Ruijven J, Du GZ (2011) The effects of long-term fertilization on the temporal stability of alpine meadow communities. Plant and Soil, 345 315-324

Yang HJ, Jiang L, Li LH, Li A, Wu MY, Wan SQ (2012) Diversity-dependent stability under mowing and nutrient addition: evidence from a 7-year grassland experiment. Ecology Letters, 15, 619-626.
Zhang YH, Han X, He NP et al. (2014a) Increase in ammonia volatilization from soil in response to $\mathrm{N}$ deposition in Inner Mongolia grasslands. Atmospheric Environment, 84, 156-162

Zhang YH, Lü XT, Isbell F et al. (2014b) Rapid plant species loss at high rates and at low frequency of $\mathrm{N}$ addition in temperate steppe. Global Change Biology, 20, 35203529.

Zhang YH, Feng JC, Isbell F, Lü XT, Han XG (2015a) Productivity depends more on the rate than the frequency of $\mathrm{N}$ addition in a temperate grassland. Scientific Reports, 5, 12558

Zhang YH, Stevens CJ, Lü XT, He NP, Huang JH, Han XG (2015b) Fewer new species colonize at low frequency $\mathrm{N}$ addition in a temperate grassland. Functional Ecology doi:10.1111/1365-2435.12585.

Zhu JX, He NP, Wang QF, Yuan GF, Wen D, Yu GR, Jia YL (2015) The composition, spatial patterns, and influencing factors of atmospheric wet nitrogen deposition in Chinese terrestrial ecosystems. Science of the Total Environment, 511, 777-785.

\section{Supporting Information}

Additional Supporting Information may be found in the online version of this article:

Table S1. Results of two-way ANOVA for the effects of the frequency and rate of nitrogen addition and their interactions on the ecosystem temporal stability, ecosystem mean, ecosystem standard deviation, population stability, and species asynchrony.

Table S2. Results of three-way ANOva (with the treatment $\times$ species richness interaction term) for the effects of the frequency and rate of nitrogen addition, species richness, and their interactions on the ecosystem temporal stability, ecosystem mean, ecosystem standard deviation, population stability, and species asynchrony.

Figure S1. Nitrogen-induced changes in ecosystem temporal stability, species asynchrony, species richness, and ecosystem mean and its standard deviation.

Figure S2. Relationship between ecosystem stability, species richness and $\mathrm{N}$ addition rate using the data in Hautier et al. (2015). 